\title{
Primera aproximación al bosque El Imposible
}

\begin{abstract}
"Son las montañas las que tienen virtudes; por eso, antes, cuando había más montañas, la gente veía cosas raras y se encontraba con animales extraños. Ahora, que ya casi no hay montañas, han desaparecido las virtudes y casi no se oyen historias de aparecidos o de encuentros con animales extraños".
\end{abstract}

Vidal Campos, guardabosque del parque El Imposible.

\section{Desde el portón de entrada al casco de la hacienda}

Caminar por las veredas de El Imposible es toda una experiencia de contacto con un mundo magia y de fantasía. Pero no de esa magia y fantasía de plástico, a las que estamos tan acostumbrdos por el cine y la televisión. Ahi, en El Imposible, hay un embrujo como el que tiene la masacuata, según nos cuenta el padre Fray Francisco Ximénez, en su libro Historia natural del reino de Guatemala. Las masacuatas o culebras-venado (del nahuat, masat=venado; coat = culebra), sobre todo las especialmente grandes, ostentan cuemos -dice, más o menos Fray Francisco Ximénez - y son capaces de ejercer una fascinación o hipnósis sobre sus víctimas. De modo que algunos animalitos, como los venados pequeños, son atraídos, inermes, por la enorme culebra.

El venadito es tragado entero por la "boa constrictor" centroamericana (de ahí su nombre de culebra-venado : o por los cuemos que parecen de venado, o porque es capaz de engullirse un venado). Pero esa fascinación puede ejercerla la masacuata hasta con seres humanos - continua el padre Ximénez-; y la manera de romper el hechizo, que proviene del "juelgo" (del aliento) del animal, es tirando un poco de agua entre la culebra y la victima que se dirige embelesada a las fauces de su victimaria.

Pues bien, el "juelgo", el vaho o aliento húmedo y denso de las montañas 
(selvas y bosques) de El Imposible, es diffcil resistirlo. Irse internando por las sendas que conducen a los lugares o guaridas en que esconde sus encantos es ir hipnotizado, alelado, al encuentro de lo misterioso, donde la muerte y la vida se hermanan con una naturalidad que espanta.

El mismo nombre, El Imposible, le provino al lugar porque no hace mucho tiempo había en una de las cumbres más altas un paso casi "imposible" de franquear. Ese paso era obligado para quienes querfan ganar tiempo en su viaje a pie o en bestia desde San Francisco Ménendez hasta Tacuba. "Era bastante imposible pasar", nos dice don Orlando Santos, jefe de guardabosques del parque; y utiliza el término "imposible" por "muy difícil". Porque él mismo nos recuerda que sólo los indios mecapaleros - con su carga a la espalda, asegurada con una cuerda en la frente- se atrevían a semejante hazaña. Los ladinos casi no lo hacían, porque ya a las 6 de la tarde, por ejemplo, se formaba en el lugar una densa neblina que no dejaba ver casi nada. $Y$ asl, era peligroso que el tigre (el jaguar) o el león (el puma) se comiera a los atrevidos caminantes.

El paso de El Imposible era un encuentro y un reto con la muerte. Durante este 1 de noviembre que estuvimos en la cumbre más alta de El Imposible, don Orlando Santos nos contó cómo fue hecho el primer puente, hace aproximadamente unos 40 años. Pero, para llegar a los detalles de esa narración debo dar cuenta antes de los lugares por los que fuimos pasando y los episodios que los guardabosques nos fueron relalando.

El grupo expedicionario del programa "Flor y Canto" de YSUCA estaba formado por Oscar Melhado y yo, como responsables del programa; Ana Mará Membreño, novia de Oscar; Camila, de 3 años, hija de Ana María; Ursula, de 12 años, mi hija; y Margarita, joven que cuida a Camila.

A la entrada del bosque, justo al término de una de las calles de San Francisco Menéndez —en el departamento de Ahuachapán - se encuentra la casa de don Orlando Santos, jefe de guardabosques de El Imposible. Como la vez anterior, hicimos parada ahl para entregar la carta en que se autorizaba nuestra visita y para que alguien nos acompañara por el interior del parque. Hace unos meses fue el mismo don Orlando quien amablemente nos sirvió de gula; pero ahora, en vista de que don Orlando no había regresado aún de su ronda de vigilancia, fue su hijo Carlos, de unos 15 años, quien nos acompaño.

Dejamos el vehículo -una trooper de la familia Melhado —en el lugar de nuestro campamento del viaje anterior, a unos 5 kilómetros de la entrada del parque. Luego, seguimos a pie montaña arriba; eran las 11 y 30 de la mañana.

Saltando entre piedras, atravesamos el rfo San Francisco, asegurando a Ursula y a Camila que podran bañarse en el rlo cuando estuviéramos de regreso desde las cumbres. Por otra parte, tal como le habla prometido a Victor Flores, jefe de producción de YSUCA, yo iba preparado con una grabadora para captar in situ 
los sonidos del bosque y las voces nuestras que consignaran las impresiones de la travesía.

Este es el programa Flor y Canto (inicié yo con la voz jadeante y temblorosa de quien no ha agarrado aún el aire suficiente al subir una pendiente)... llegando a ustedes desde el lugar mismo de los hechos... desde el hermoso parque natural... de El Imposible... Queremos llevarles a ustedes las incidencias de nuestra expedición... transmitidas par la voz misma de sus protagonistas... Queremos que viajen con nosotros por este reino del canto y de la flor... Porque aquí canta el viento y hasta canta el silencio... Aquí también todo es flor: desde la colorida campánula silvestre o la coqueta orquídea... hasta las huellas que van dejando sobre el lodo fresco, los mapaches, los venados y los tepescuintles...

'-¿Cómo te llamás?' '-Camila'. '-iY quién viene contigo?' '-Mi mami'. '- ¿Y cómo se llama tu mami?' '-Ana María'. '-iQuién te va chineando?' '-Oscar'. (Se oye enseguida la voz de Oscar): '-iQué animalitos querés ver en el bosque?' '-Tambor y bambi...'

En estos momentos estamos pasando por el lugar que llaman Rancho Quemado... porque, según los decires de las gentes... vivian aquí dos señores, dos viejitos. Un día el señor se fue a trabajar y al volver no encontró a su esposa. Salió a buscarla y a llamarla por el bosque... Y entonces fue encontrando los restos ensangrentados de su esposa. El tigre se la había llevado y la había ido devorando. Casi enloquecido por el dolor, el anciano quemó el rancho y abandonó el lugar... De ahi que le quedara el nombre de Rancho Quemado a esta pequeña explanada, ahora ya casi cubierta por la vegetación..

Aproximándonos al Mirador se cruza ante nosotros una mariposa de hermosas y enormes alas azules... (Se oye luego la voz de Ursula): '-Esta mariposa nos ha venido acompañando desde abajo... parece que quiere indicarnos por donde es que sube el camino..."

Hemos llegado al Mirador, un conjunto de riscos y peñones que tienen una altura aproximada de 700 metros sobre el mar... La vista, desde aqui, es formidable... Al sur se ve el mar y la amplia planicie costera... El río Paz que divide las repúblicas de El Salvador y Guatemala.. Al norte, al este y al oeste, las montañas que forman parte de la reserva ecológica de El Imposible... - ¿Qué te parece, Ana María, esto que estamos viendo? -Realmente maravilloso (contesta Ana María); sólo la mano de Dios pudo hacer tanta belleza; tanto detalle de formas y colores... (Interrumpo yo): -Fijate en esos parches blancos que se ven entre el verde de las montañas de enfrente... son pascuillas. Aquí tenemos una pascuilla cerca de nosotros, junto a este barranco. Mirá como se ha llenado de florecillas blancas... 
Ahora vamos a pasar al otro peñon que forma parte del Mirador (Se oye un casi grito de Ana María dirigiéndose a Camila: '-iNo te acerqués, no te acerqués... que puede haber alguna piedra floja...!") Hay un puentecido formado con delgadas ramas de árbol... Y ya estamos en el otro peñon...

$Y$ es entonces que se nos concedio lo que desde la vez anterior habfamos anhelado: ver en vuelo a un gavilán blanco. Debajo de nosotros, en la hondonada que forman dos montañas, volaba majestuoso un gavilán blanco, blanquísimo, como si fuera un ave albina, aunque con un pequeño ribete negro en la punta de las alas.

'- ¿Y cómo le llaman a esa ave, Carlos?' (pregunto emocionado) '-Le llaman Gavilón Rey; porque sólo él es blanco, mientras los demás gavilanes son de plumaje oscuro' '- $i Y$ hay varias parejas aquí de gavilanes blancos?' (insisto yo) '-Si, hay varias parejas; pero mire, don Lito, ahi va volando también un Rey Zope'.

Majestuosas volaban las dos aves, como dueños y señores de los acantilados. El Rey Zope, el cóndor centroamericano tiene en El Imposible uno de sus últimos santuarios que le han dejado los salvadoreños. Junto con el cóndor de los Andes - en el sur-, el cóndor de California, —en el norte-, el cóndor centroamericano o Rey Zope, forman la tríada de aves más grandes y majestuosas del continente americano.

Sólo falto para que hubiera estado complete el espectáculo, el vuelo increßble del Aguila Crestada (me imagino que es la misma Harpía de Suramérica); un ave que la vez anterior creímos ver volar sobre nuestras cabezas, mientras visitábamos la Cueva de los Cabros.

Después de haber permanecido par unos momentos en el Mirador proseguimos nuestra caminala hacia el casco de la hacienda El Imposible.

Una peña grande cubierta de musgo y de parásitas nos indica que ya estamos cerca de la Cueva de los Cabros... aunque en esta ocasión no vamos a visitarla por cuestión de tiempo...

La vez anterior sí estuvimos en ese impresionante lugar, llamado por los habitantes de la región, la Cueva de los Cabros, la Cueva del Tigre o la Cueva del Pedrerón. Se trata de un peñón enorme, como de 50 metros de altura, del que se desprende una delgada pero hermosa cascada. Después de formar una pequeña poza, el agua continúa montaña abajo entre una densa vegetación formada por árboles y arbustos de nombres tan pintorescos como: Molleja de pato, Polvo de queso, Copinol, Viril de venado, Chimichaca, Escobo negro, Tercio de pelo, Teresa, Cafecillo, etc., etc. (Por cierto, don Orlando Santos es loda una enciclopedia viviente en eso de dar cuenta de las características y nombres de árboles, plantas y animales). 
Debajo de la cascada se ha formado una cueva bastante grande, y ahf - siempre durante la anterior visila - don Orlando nos fue enseñando las huellas recientes de mapaches, que habían llegado durante la noche anterior en busca de cangrejos; huellas de tepescuintles, que hablan hecho un caminito entre el lodo; huellas de venados, juguetones y desprevenidos, y hasla vimos dónde, hacla unas horas, se hab́an estado bañando con tierra los pajuiles y las pavas.

En esa ocasión nos contó don Orlando que hace muchos años llegaba a la Cueva del Pedrerón un brujo; ahí hacía sus oraciones y sus maleficios. La rajz de su fuerza y de su poder estaba en un libro que poseía: el Libro Infernal. Un día los soldados le quitaron el libro, se lo quemaron; y el brujo se fue entristeciendo, entristeciendo, hasta que se murib.

Ciertamente, el lugar no deja de provocar alguna aprensión, con todo y lo bello que es. La densa vegetación sólo se abre un poco cerca del peñón, formando hacia el cielo una especie de enorme ventana. El paraje, en consecuencia, es algo oscuro y húmedo... propio para que la imaginación de las gentes lo adornen con relatos de embrujos y de aparecidos.

Cerca de nosotros, en dirección a la Cueva de los Cabros están volando unos pericos. Según nos informó la vez anterior don Orlando, dichas aves son asiduos visitantes de estos parajes porque aquí abunda el duraznillo, una fruta pequeña, como de $15 \mathrm{~mm}$., pero de un saber muy parecido al del durazno. Dicha fruta es, pues, un manjar para los pericos...

En aquella ocasión yo recogí una buena provisión de duraznillos y me entretuve durante el camino saboreando la fruta preferida de los pericos de El Imposible.

\section{Las "pasadas" de don Vidal}

A las 12 y 30 del mediodía ya habíamos llegado al casco de la hacienda. Descansando estábamos en los corredores de la casa, cuando se presentó don Vidal Campos, otro amable guardabosque quien, en el viaje anterior, nos había entretenido con sus historias y consejos. Ahora, yo ya venía preparado y, casi desde el comienzo, grabé la conversación con don Vidal.

Don Vidal Campos lleva unos 13 años trabajando cono guardabosque en El Imposible (introduje yo al personaje); tiene 52 años y está ansioso par contarnos las aventuras que él y conocidos suyos han vivido por estos parajes...

Lo primero que nos informó don Vidal fue acerca de la Cueva de los Cabros. Le pusieron ese nombre - nos dijo- porque el anterior dueño de El Imposible, don Pedro Mezquita, tenía una crianza de cabros y ovejas. Estos animales no son muy adictos al agua; por eso, en el invierno, cuando salían a pastar montaña abajo y les agarraba la lluvia, si estaban cerca de la Cueva, pues se metían en 
ella para pasar la noche. Al día siguiente, cuando ya había amainado la lluvia, los cabros y las ovejas subían al casco de la hacienda.

Huyendo de la lluvia, los cabros le dieron el nombre reciente a la Cueva, asi como años atrás algún tigre se lo hubo dado también por haber hecho de aquel lugar su guarida. La Cueva de los Cabros, la Cueva del Tigre o la Cueva del Pedrerón; muchos más nombres podría tener ese paraje que embruja... Pero, en vez de sacar conclusiones como ésta, me interesaba consignar de viva voz, las experiencias que nos pudiera contar don Vidal.

Les voy a contar sobre la cara que salia de la peña (prosiguió entusiasmado don Vidal). A mi me gustaba salir a cazar con un señor llamado Gilberto Garcia; porque aqui, antes, era bueno para cazar animales; y el tal don Gilberto tenía suerte para andar cazando. Cuando él tiraba, uno tenía segura la comida de carne. Si saliamos de día, podiamos cazar pezotes, pavas y pajuiles...

Esa vez nos fuimos para la montaña del jutal; se le nombra así porque anteriormente, cuando yo era cipotón, los jutes se juntaban ahi como si fuera un pedrero; y alli uno escogía el más grande. Porque eran groserías de jutes. Y para allá nos fuimos nosotros a velar esa vez.

-Si querés vamos -me dijo Gilberto-; fijate que hay unos jocotes buenos; tal vez se asoma algún pezore o llega algún pajuil'.

Eran los tiempos de agosto y estaba en lo mejor la cosecha de los jocotes de pava; el jocote de pava es una fruta silvestre al que le llaman asi porque es la propia comida de las pavas. Pues estaba el palo de jocote abajo y nosotros nos trepamos en otro palo de jocote que estaba asi, arribita. Nosotros habíamos llegado como a eso de las 3 de la tarde, para estar esperando tirar como a las 4 o 5 .

Pues como que ya iban a ser las 5 cuando oímos un ruidito, unas piedritas que rodaban de la peña Vino aquel y voltió a ver. '-Parece que par ahí vienen los pezotes; estate callado'; -me dijo-, cuando al rato voltio a ver a la pura roca de la peña.

Esa peña está en un desfiladero; es un solo corte el que está así. De ahí nace el agua, la quebradita esa del jutal. '-Mirá, vos, lo que está ahí, en la peña' -me dijo Gilberto-; y cuando yo voltié a ver, vi la cara de una virgen: pura la Virgen de Fatima; así como aparece en las estampas y en la iglesia.

La peña esa está como si la hubieran lustrado, como si le hubieran echado cemento: blanca se mira. Pues entre medio de lo blanco se miraba la cara asomándose como por una ventanita. 
'-Agachá la cabeza; mirá para'bajo; no la mirés mucho, porque ya sentí un miedecito' -me recomendó Gilberto-. El era el de más valor ahi; porque ya era un hombre adulto y yo era apenas un cipotón. Por eso, yo también sentí un poco de miedo y voltié a ver para'bajo.

Pero cuando uno está cipotón uno sólo es malicia: cuando mira algo, quiere voltiar a ver otra vez; yo así era. Sólo que al agacharme otra vez así para'bajo, quizás como a los 10 minutos, en la peña ya no había nada.

'-Fíjese que ya no hay nada' -le dije a Gilberto-. '-iEh...! ¿Ya no está?' $Y$ voltiamos a ver y ya no había nada; nada, nada. '-Vámonos, vos -me recomendo él一; fijate que no vaya a ser que nos agarre la noche, y sea alguna cosa que nos pueda jugar, y vamos a quedar asi, todos perdidos'.

$Y$ así nos venimos; no tiramos nada, porque no esperamos a que llegaran los animales.

Oyendo a don Vidal Campos, uno creería que está ante una persona insensible que habla con la mayor naturalidad y desenfado de sus cacerías recién pasadas. Algo que no pega con el cargo y el trabajo que ahora desempeña don Vidal. Porque los guardabosques de El Imposible, precisamente, tienen que proteger a los animales y a las plantas de la acción irresponsable de cazadores y taladores legales y/o furtivos.

Sin embargo, es un hecho que don Vidal Campos ya no es un cazador, sino todo lo contrario. Es un vigilante que impide la cacería y que, además, hace su trabajo con amor y convicción. Yo entiendo ese cambio de actitud en don Vidal: yo también fui un cazador fanático, $y$ ahora soy un preservador a ultranza de animales y plantas. Quizás la única diferencia con respecto a don Vidal sea que yo hablo y platico con vergüenza de mi época de cazador.

Don Vidal parece disfrutar narrando sus aventuras como cazador de pezotes, pavas y pajuiles. En realidad, yo creo que don Vidal disfruta narrando... contando aventuras. Eso es lo principal; lo secundario es que lo narrado sean escenas de cacería o un episodio de aparecidos. Don Vidal es un narrador popular, un cuentero nato... de esos a quienes no se les dice dos veces para que cuenten una pasada. Porque a la primera insinuación ya van buscando acomodo en una piedra o en un taburete... y empiezan a echarse el cuento.

Esta es una pasada que a mi papá le pasó (continuó don Vidal) en tiempos de su juventud. El era originario de Ataco; ahí habia nacido; ahí tenía toda la familia y muchos amigos. Tenía un amigo por el lado de Jujutla, en una parte que nombran Las Mesas.

Una vez a mi papá se le ocurrió ir a ver al amigo. Con él se nombraban únicamente por "compas"; asi se entendian bien. El amigo de mi papá era de pisto también, pues mi papá tuvo pisto en aquel tiempo. Cuando llegó a 
la hacienda del señor ese, le dijo mi papá: '-Hola, compa...', porque el señor ahi estaba. '-Hola, iqué milagros, hom', compa...!'. '-Sí, me decidí a venir ahora para ver si Ud. tiene algún punto bueno para ir a cazar algo. para ir a tirar...' '-A $h$, mire, compa, fijese que ayer fui al potrero a ver al ganado y vi que hay dos palos buenisimos: está un palo de sempisque y está otro palo de amate; asi es que a'i vea cuándo se viene'. '-Me voy a venir listo y vamos ir a tirar; me voy a venir mañana tempranón' '-Vaya, pues'.

Mi papá se estuvo toda la tarde con su amigo, y ya cuando se estaba haciendo noche, agarró camino, de vuelta a su casa para prepararse. Sacó su escopeta, su lámpara... y todo. Al día siguiente se fue adonde el amigo a eso de las 12, a almorzar ahi. El amigo le dijo: '-Bueno, compa, nos vamos a ir después de almuerzo; ya ahora la luna sale temprano, asi que los animales van a salir temprano también'.

Se fueron, pues, como cosa de las 3 de la tarde. Llegaron al primer puesto, que era el palo de tempisque. El amigo le dijo a mi papa: '-Mire, compa, éste es el primer palo, y el amate está allá arriba $A$ 'i vea si se queda aquío se va a quedar allá arriba'.

'-Vamos a ver el amate', dijo mi papa; y se fueron a ver ese otro palo; estaba lo mismo que el palo de tempisque: picado lo tenían los animales, como si fuera algún corral de ganado. Rastral, huellas; y se veía que los animales no dejaban que se cayeran bastantes frutos porque todos se los comian... los venados.

- -Me voy a quedar aqui en el amate', le dijo mi papá al amigo. '-Entonces, me voy a ir al otro palo, al de tempisque', le respondió el amigo.

Estaba junto al amate una piedrona que - según nos cuenta mi papá- era quizás como del porte de esta casa (la del casco de la hacienda El Imposible). Sobre la piedra habia nacido un palo de chichicaste que tenia tres horquetas. Pues ahi entre las tres horquetas se quedó mi papó, se posesionó... para esperar a que llegara algo.

Ya había empezado a pardiar la noche, pero como la luna estaba de llena, a las 6 de la rarde había salido ya. En eso mi papa oyó un ruido que venía ast, del lado de abajo. Porque mi papá estaba sobre la piedra y abajo estaba una joyadona, un plan donde estaba el palo de amate. De ahi para abajo era una planiza, pues...

Cuando mi papá oyó el ruidito se puso listo con la escopeta, preparó bien su Lámpara Pero resulta que el ruido dilataba en llegar adonde él estaba, porque conforme la luna iba trepando, asi se le iba acercando también el ruidito aquel.

Como a eso de las 9 de la noche la luna había trepado un poco más y empezó a foquiar toda la parte donde estaba mi papá; el ruido ése iba más 
cerca y más cerca... Y mi papá listo con la escopeta y la lámpara... Se miraba bien, bien...

Cuando el ruido llegó a unos 10 metros de distancia, brotó un hombre; pero un hombre -según nos contaba mi papá-inmenso y con un gran sombrerón. $Y$ cómo sería de grande el hombre porque mi papá estaba sobre la peña y el hombre estaba abajo, en la joyada.. pero los dos estaban frente a frente... como estamos nosotros aqui viéndonos... cara a cara.

Mi papa se asustó. Tenía la escopeta ya lista, pero cuando vio al hombre aquel no se acordó de nada; la escopeta se le quedó prendida asi, entre las piernas. Mi papá dice que el hombre no le hizo nada de malo. Lo único fue que cuando se estaban viendo, el Sombrerón pegó un pugido; un pugido ordinario... '- iHuu... juumm...!' Y mi papá dice que la piedra temblo ahi donde él estaba sentado. Imagínese cómo podía ser de grande esa piedra.. y la piedra se menio...

Mi papá viendo aquel pugido se acabó de morir más. El Sombrerón sólo eso le hizo y agarró camino. Al rato... que volvio el espiritu a llegarle a mi papá, que se le habia ido algo el miedo... puso las manos en las piernas y se tentó la escopeta. '-Pero, hom' -dice que dijo-; teniendo la escopeta y no le tiro yo a este hombre; iqué lástima! Pero mejor me voy, no vaya a ser que le salga a mi compadre y lo vaya a asustar también'. En eso se bajo de la peña y se fue yendo, se fue yendo... Desde que iba llegando, le iba silbando al compa.

El amigo oía que mi papá silbaba, pero como ya había oído también el ruido, esperaba que fuera algún venado. '-iCompa, compa...'. '-iQué es lo que le pasa, hom' compa?'. '- Vámolos; vámolos! y hay le voy a contar...'. '-Pero hom'compa; a Ud. nunca le habia pasado esto; ¿miedo es lo que le ha entrado?'. '- No, compa, me ha pasado una cosa que le voy a contar'. '-A Ud. quizás es el miedo el que lo está fregando. Si, mire; a'i nomás viene el venado; a'i nomasito se oye el ruido'. '-iNo, compa; si no es venado...!". '-Pues, hom'compa, al fin vómolos. Pero, no vamos a llevar came porque Ud no quiso... y porque mucha bulla está haciendo. Ud. miedo tiene'. '-No, compa, ¡vámolos!'. Y entonces, agarraron camino.

Yo cuando habian caminado un poquito, dice mi papa que le dijo el amigo: '-Pues, sí, compa, ¿y qué es lo que le pasa a Ud.?'. '-Mire, a mi me ha salido un hombre; pero se admirará Ud... ordinario de grande; y con un gran sombrerón'. '-No creo', le dijo. '-iCómo no, compa; si hasta mucho serb́ que no nos salga por aht! Ese ruidito que Ud. oía... ese era; porque así merito me llegó a mí también: como forma de ruido de venado... porque los pasitos que da, puros pasos de venado...' '-iAh, pues, sl, compa; entonces, vámolos!' 
$Y$ se fueron caminando, caminando... Y tenían que salir ellos a un potrerón del señor ése; ahi donde tenía el ganado... Era un puro plan; y, a mediación del potrero, estaba un pal6n de ceibo... Pues cuando salieron a la claridad, donde estaba el potrero, vieron para adelante... y ahi estaba El Sombrerón.

'- ¡Compa, compa; mire!'. '-iDe véras, compa; pútchica!', dice que le dijo. '-iFíjese que yo lo tuve asi, frente a frente... y me pegó un gran pugido... que viera qué susto me dio. No ve que yo no me encontraba la escopeta ni nada... porque yo senti que me mori un rato!'. "-iAh pues, si, compa....'

A una distancia de unos 30 metros iba El Sombrerón adelante de ellos; y si ellos se paraban, se paraba también El Sombrerón... Si caminaban, caminaba. Entonces ya ellos iban con miedo... Y como antes, al que era tirador no le faltaba su paquete de puros y una su botella de guaro. "-iMetómolos un trago, compa, para agarrar valor; porque no vaya a ser que nos agarre este Sombrerón... asi, sin nada!'

Bueno, pues, se metieron un traguito; y El Sombrarón ahi parado... haciéndoles tiempo. Al ver que no se iba el hombre, pegaron otros pasitos... y otros pasitos El Sombrerón. Se pararon ellos; se volvió a parar El Sombrerón. 'Compa, tomémolos otro trago...' Se metieron otro trago y encendieron un puro y se lo fumaron ahi no más; y es que en ese tiempo no usaban cigarro sino sólo puro.

Y ya con la reacción de los dos traguitos, dice que le dijo mi papa: '-Mire, compa, topemos a este hombre; pero, eso sí, como ya está para llegar al palo de ceibo, vamos a ver si lo podemos topar antes de que se esconda en el palo ése. Así que Ud. le llega por un lado y yo le voy a dar por este otro lado. Si Ud. lo mira más luego, hace una señal: pega un chiflido, para tirarme yo al suelo...'. '-Va, pues', dice que le dijo el amigo.

Hicieron ya ese arreglo y se fueron. Cabal, -dice que ahi se metio el hombre bajo la sombra del palo. Y como ellos ya habian visto que ahí estaba, se fueron acercando con las escopetas listas... Pero cuando llegaron a la mitad del palo, se toparon los dos y ya no había nada... Y solamente ese palo estaba... y ya no podía esconderse el hombre por otro lado

$Y$ hasta ahi los dejó el hombre Sombrerón; hasta ahi en ese palo; porque ya de ahi para alla ya se fueron tranquilos... solamente contando el cuento de lo que les había pasado.

El Sombrerón o ese ser misterioso que "broto" del suelo —según nos relata don Vidal Campos- era un hombre alúsimo. $Y$ al ofrlo, me vienen a la memoria esos hombres en zancos que hasta hace poco tiempo formaban parte de los pregones en las fiestas de Santa Ana y de San Salvador. Para mi, de cipote, siempre fue un misterio cómo es que se mantenian en equilibrio esos hombres 


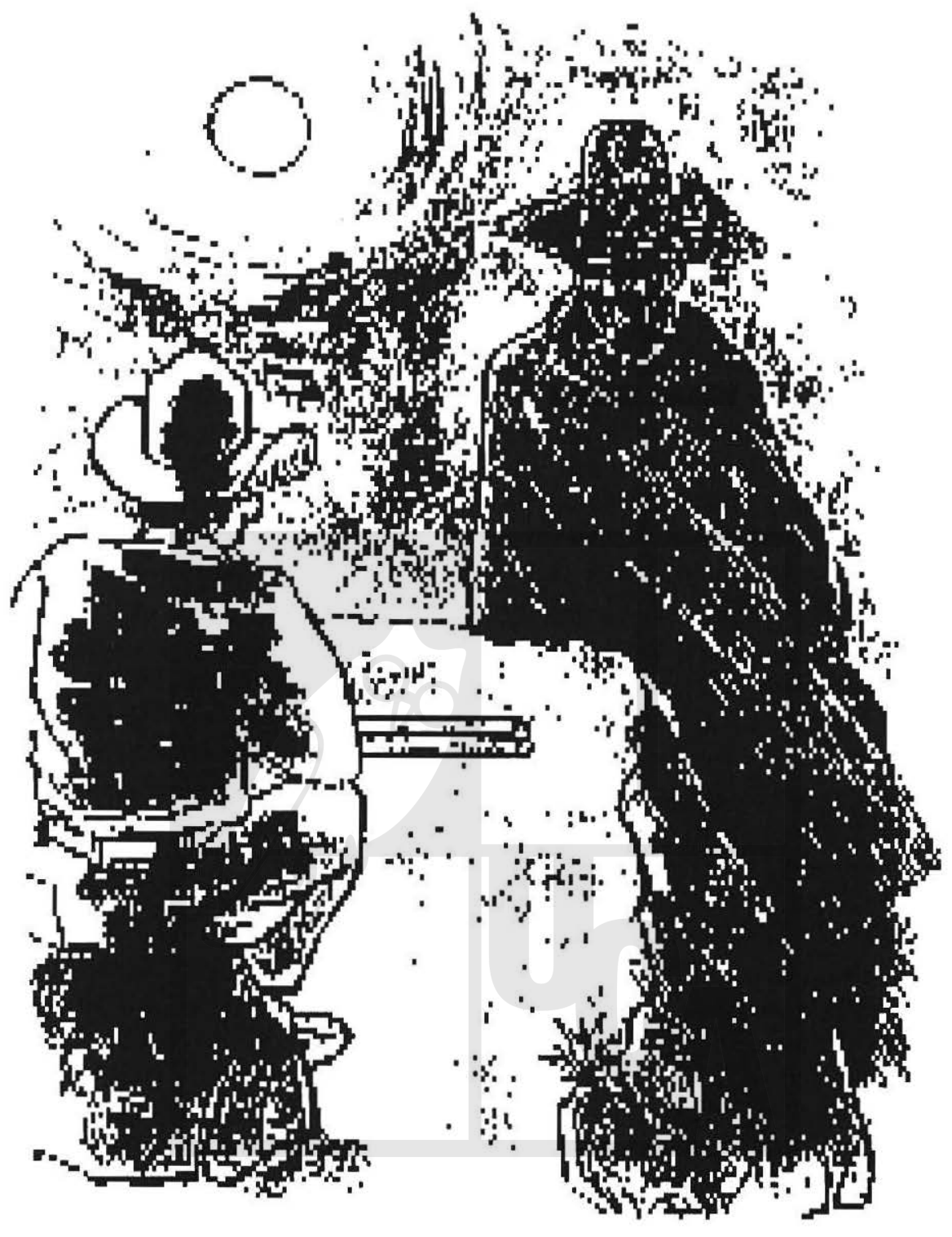

Brotó un hombre inmenso y con un sombrerón 
encaramados en zancos tan altos... si a ml me costaba un mundo caminar en unos zancos chiquitos. Por eso, los gigantes de las fiestas julias o agostinas ejercieron sobre mí una mezcla de miedo y de fascinación, con sus enormes patas de madera y con sus larguísimos pantalones vueludos, agitándose como banderas al viento. El Sombrerón - pienso ahora- tuvo que haber sido del tamaño de esos hombres sobre zancos...

Pero El Sombrerón ha sido asociado también, en la mitología popular, al Justo Juez de la Noche. Yo me imagino que esta asociación se debe a que $\mathrm{El}$ Sombrerón imparte alguna forma de justicia. Por ejemplo, en el caso de aquellos cazadores —el papá de don Vidal y su compa-, aquel misterioso ser altísimo impidió que fueran cazados y sacrificados quién sabe cuántos venados. El Sombrerón fue, entonces, una vía misteriosa - patética y hermosa a la vez- de exteriorizarse, de corporizarse la mala conciencia de los cazadores. Porque es lindísima la idea esa de que El Sombrerón caminaba cuando ellos (los cazadores) caminaban; y se detenfa cuando ellos se detenfan... para darles tiempo a que tomaran aire y descansaran. Recordemos, además, que don Vidal insiste en el relato en que su papá se sintió paralizado y no pudo usar su escopeta. El pugido que hizo temblar la piedra y "morirse" al papá de don Vidal, podría interpretarse también como el equivalente a un reclamo y un lamento surgidos de la entraña misma del bosque.

El Sombrerón, el Justo Juez de la Noche velaba en aquellas montañas aún vírgenes porque se respetara la vida alegre y desenvuelta de los animales... ¡Hermosa alegoría (es decir, personificación dramatizada) esta que representa El Sombrerón o el Justo Juez de la Noche! El Sombrerón desapareció bajo la sombra de un enorme ceibo - concluyó don Vidal su relato- confirmando, inconcientemente quizás, que se trata de una especie de espiritu custodio de las montañas y bosques. En el decir del propio don Vidal: un ser que "brota" del mismo suelo y que se oculta y desaparece luego bajo la sombra de un árbol gigantesco. Un ser, en suma, que es emanación y que forma parte del "juelgo" de la montaña.

Por otro lado, don Vidal Campos nos aclara que esta "pasada" que acaba de contarnos le ocurrió a su papá cuando era aún joven, de unos 25 a 30 años. Como el papá de don Vidal murí́ hace 26 años, a la edad de 60; pues en ese momento calculamos con don Vidal que estábamos hablando de unos 60 años atrás. De pronto, en el relato de ese guardabosque de EI Imposible, nos habíamos trasladado a la década de los 30 en El Salvador, época en que, ciertamente, habra una flora y una fauna más abundantes en el país; pero también una problemática social muy marcada; es decir, un clima y una atmósfera aptas para que proliferaran, a sus anchas, los duendes.

La persuasión de que son las montañas mismas las que "producen" estos espíritus y visiones, aparece expuesta en el epígrafe de esta crónica. No puse ahí las palabras textuales de don Vidal... Hice, más bien, una parárasis; pero tratan- 
do de ser fiel a todo el trasfondo de poesía que hay en sus palabras.

Pero,ahora, dejemos que sea el mismo don Vidal quien siga con sus narraciones:

Les voy a contar esto que a mi papá le pasó siempre en asuntos de cacería. Mi papá tenía dos escopetas: una viejita y otra nuevona... de haberla comprado; y esa nueva fue la que quería estrenar. Entonces tempranón se regresó del trabajo para su casa y le dijo a la mujercita que tenia: -Mire, hoy me vine temprano porque quiero ir a ver si mato algún animal para comer algo mañana... Deme almuerzo, pues'.

Asi que almorzó y descansó un su rato, ya se fue para una montaña ahi por donde ellos viviam ast para'bajo. Este caso le paso ahi por Jujutla. Pues así que comió, agarró la escopeta y se fue. Era una montaña donde habian juitales, nísperos, chaparrones, amates y toda clase de árboles... Era un bosque virgen. Pues mi papa bajo una quebrada, un barranquito. Era una quebrada donde pasaba agua en el invierno... Ahi habia caido un palo de níspero que había quedado como puente de un lado al otro... y entre medio estaba la quebrado que -según nos contaba mi papa-podía tener unos 10 metros de honda.

Ahi estaba en la quebrada cuando mi papá oyó un ruidito que venía así.. y al ratito él vio que brotó un animal prieto... pero con una piel chula. El animal pasó por ese palo que esiaba caído y mi papá estaba abajo. Pues dice que dijo: '- $i$ Cómo fue que no le tiré a este animal? ¿Qué bonito... ¡La piel ;qué bonita...!"

Pero al ratito, dice que otro... '- ¡A este sí le voy a tirar!' Montó la escopeta y le tiró.. Le pegó y le quebró la pierna. El animal cayó al suelo; entonces dijo a pepenarlo. Pero cuando mi papá dice que topó, el animal ése se puso furioso... se le pegó una aventada. Vino mi papá y se aparto; agarró la escopeta de la culata al lado de la caja. Al aventársele el animal li'ace el pencazo con la escopeta, a modo de pegarle con el cañon. El animal se le fue para un lado, pero del pencazo que le dio, la escopeta se quebró cabalito en la mitad. Le quedó sólo la culatilla... de la escopeta nueva que andaba estrenando.

El animal se le fue otra vez encima... y él sólo quitóndoselo... quitándoselo, como si estuviera peleando con alguna persona. Pues dice que al rato, él ya cansado; porque -según nos contó él-a ese animal le tiró como a eso de las 3 y media de la tarde; y eran casi las 4 y media y él todavía peleando con aquel animal... después que lo habia baleado.

Entonces dice que el animal, cuando se cansaba, pegaba un silbido y se metía en una cuevita de un paredón que estaba así.. El silbido era la señal que daba el animal de que estaba cansado y de que quería descan- 
sar... El animal silbaba y se arrinconaba en ésa cueva. Y mi papá cansado, bañado en sudor... Ya asi que iba a salir, el animal le pegaba un silbido otra vez para que mi papá se preparara... Así que silbaba el animal, al ratito le brotaba y decía con mi papá otra vez... Mi papá sólo quitándoselo, defendiéndose.

Después de un rato, como el animal, cansado, ya poquito peleaba y se volvía a arrinconar en la cuevita esa; entonces dice que le dijo mi papá: - iAh no; hoy si ya me enojaste; y si estoy asi con vos, ni voy $a$ ir entonces a la casa; me va a agarrar la noche aquí; asi que sall y vamos a pelear... hoy sí vamos a pelear!' Entonces, dice, que con la culata le pegó el trabón; pero al trabón ya lo tenía así a la par. '-iCon gente!', dice que dijo mi papa ... y ahí le tiraba mi papa a quererle dar duro

Al fin de tanto, al rato de estarle tirando con ganas, le logró pegar un culasazo en el sentido, en la cabeza... El culatazo ya le dejó azurumbado y al fin lo logró vencer. A todo esto ya era bastante tarde... como las 5 y media. Y tenía que trepar una cuesta, así para"rriba.. Y ya arriba era una milpa, una explanada... y ya ahí para'bajo del plan... eran las milpas de ellos... El abajo vivía.

Agarró al animal de la cola y se fue para'rriba. Pero ese animal, cuando iba caminando mi papá con él a rastras, ramita que agarraba... los rollos de hojas que se llevaba... Todo lo que agarraba con las dos manos... para irse deteniendo... Y mi papa va de jalarlo... El ya iba afligidón porque era tarde. Pues ya casi que a las 6 logró salir arriba. $Y$ allí dice que estaba una piedrona donde ellos descansaban... Llegó al plan y tiró al animal sobre la piedra. - iVaya, gracias a Dios! -dice que dijo- que ya hoy sí estoy en la casa, porque ya de aqui está cerca'.

Mi papá encendió un su puro para descansar un poco más; cuando al ratito de estar fumando, voltio a ver al animal... y el animal se había ido levantando todo bolo... enderezándose otra vez. '-iNo te querés morir? -dice que le dijo- iHoy sí te vua matar!' Agarro una lajona y se la dejó caer en la cabeza.. Le dejó como que era tabla la cabeza... desdecha.

Pues dice que dijo: '-No, mejor te llevo ya...' Lo volvió a agarrar de la cola.. y ya se fue con el animal, a rastras para'bajo. Pero dice que asi como ibo ese animal aplastada la cabeza; porque ya no llevaba ojos... Los sesos se Los había quitado... pues, mata de maiz que agarraba todavía la iba arrancando aquel animal...

Pues llegó a la casa ya pardiando la noche. Dice que le dijo la mujercita: '- iBuenos noches; yo ya estaba afligida porque ya era de noche y no venía...!'- -iAh, cállese...! ¿No ve que este animal me ha costado matarlo? Mire, le quebré una pierna... Pero mejor no le hubiera tirade 
porque con iñolas. Pues cortó el cuero y dijo a coser el bolsón. 'Alcánceme ese bolsón viejo...' $Y$ se lo alcanzó la mujer. Entonces, mi papá dijo a sacar todo de ahí y lo metio en el bolsón nuevo.

A todo esto ya era tarde: quizás como a las 5 de la tarde terminó de hacer el bolsón. '-Mañana no voy a llevar almueno, voy a venir a almorzar aqui; asi que se levanta temprano para prepararme mi desayuno'. La mujercita mañanió: a las 4 de la mañana estaba hablíndole a mi papá: '-Vaya, don Nico, ya está el desayuno' (porque mi papá se llamaba Nicolás Aguirre).

Así que desayunó y se fue... a las 12 regresó mi papá a la casa; él ya con la malicia de querer ir a estrenar el bolsoncito. Le dijo a la mujercita: '-Deme de comer; que traigo hambre'. '-Vaya, está bueno... 'Mi papá comió, dejó que le bajara un poco la comida, y dice que le dijo a la mujercita: '- Bueno, hoy sí estó bonita la tarde para irse a pegar una perdida por a' $i$; tal vez mire algo para cazar; cualquier animalito vua traer ahora...' '-Ojala, dice que le dijo la mujercita; tengo ganas de comer carne... de véras'.

Vino mi papá, agarró la escopeta... y dijo al bolsón. '-Bueno, ¿y el bolsón?'. '-No sé', dice que le dijo. '-iQué no lo habrá guardado Ud. por otro puesto?'. '-No, yo no lo he agarrado'. '-Ah, quizás Ud. no se fijo y algún chucho se lo comió. '-No, si hoy en la mañana a'i estaba el bolsón'. '- ¿Qué se habrá hecho este bolsón?'. Y ya dice a buscarlo y buscarlo adentro... y nada. '-Pero, no puede ser... a mi se me pone que quiź́s algún ratón lo cortó de la pita, cayó en el suelo... y algún chucho se ha llevado el bolsón'. Y ya se puso a buscarlo afuera.

Del patio para allá empezaba la milpa de él. Desde que llegó a la milpa... ya vido el trillito... en el monte. "-Aqui pasó; éste ha de ser chucho... pasó con el bolsón aqui'. Y ya se fue siguiendo el trillito... siguiendo el trillito para'bajo... hasta que llegó a la orilla de la milpa, alla'bajo... $Y$ allá'bajo en el tronco de una mata de maiz: ahi estaban todos los cuentos... Ahi estaban los puros, plomos... y todo. Pero el cuero dice que no lo volvieron a ver ya... se desapareció; porque el mismo cuero ha de haber tenido virtud y se fue solo...

Al final de esta narración nos contaba don Vidal que el animal aquel tan misterioso tenía forma de perro; pero que nunca antes lo había vista su papá... y nunca más lo volví́ a ver... Y eso que el papá de don Vidal era cazador y conocía de animales. En suma, un animal con "virtud"; o, más propiamente, un animal que sería una emanación, una "virtud" de la montaña.

Algo que me llamó la atención de este último relato de don Vidal Campos es la personificación que se hace de la naluraleza: el papá de don Vidal se dirige al 
animal que acaba de cazar con la familiaridad de un padre reconviniendo a su hijo: '- $i$ Con que no me querés hacer cace? ¡Ya vas a ver el castigo que te espera!' Sólo que la traducción en el caso del cazador es más patética: '- $i$ Con que no te querés morir? ¡Hoy si te voy a malar...!'

Diálogo cruel éste que forma parte de una representación casi teatral, con escenas tan crudas y terribles como ésa del animalito destrozado, aferrándose con sus manitas a cuanta mata encuentra en el camino. Drama primitivo de la sobrevivencia éste que se llevaba acabo en el seno de las montañas aún vifgenes de El Salvador...

Por otra parte, en el relato de don Vidal todo rebosa vida, todo aparece vivificado, vívido. Eso explica por que'Ana María Membreño percibí́ a este guardabosque, durante la vez anterior que estuvimos en el parque, como una especie de historiante ejecutando su danza mientras recitaba sus parlamentos:

Me puse a pensar, cuando lo veía, que a lo major asi era el baile de los Historiantes y que en él todavia se ven trazos muy remotos de las danzas que nuestros indígenas hacian a sus deidades para expresar lo que ellos sentian en su alma.

Más que recitar fríamente su narración, don Vidal la escenifica, la actúa; y oírlo y verlo contar la pelea de su papá con el animal misterioso es una verdadera delicia, porque parece ester ejecutando pases de torero, o-como dice Ana Marfa en su escrito- pasos de la danza de un Historiante.

\section{En el mero puente de El Imposible}

Guiados por don Vidal continuamos nuestra marcha hacia el lugar "imposible". Como bichitos preguntones, cada uno de nosotros iba requiriendo del guardabosque una explicación sobre el nombre de un árbol o de algún animal. Así, nos dijo don Vidal que a un árbol de esos le llamaban soguillo o Chorrito porque el fruto que echa es en forma de soguilla (o trenza delgada); el fruto consiste en un "chorrito" de semillitas un poco más grandes que los granos de maicillo. La comen Los pájaros, los pezotes, los micoleones, los gatos cervantes y los muyuces. '- ¿Y qué es el muyús...?', pregunté yo, de curioso.

El muyúxe es un animal un poco más grande que una ardilla... es nocturno. La cola tiene anillos, como la cola del mapache... A los muyuces les gusta comer mucho de esta fruta del guarumo; pero también come hasta insectos... porque lo he visto comiendo chacuases... esos que son como langostas... Chacuate de espada, le decimos nosotros porque tiene una espada en la cola...

Don Vidal no para de hablar mientras camina. Nos cuenta que es padre de ocho hijos; uno de ellos ya es casado y tiene una hijita de 2 años. Don Vidal, 
pues, ya es abuelo; pero tiene un hijo pequeño —l chimpe- de ocho años; se llama Marvin Iovanni y viene con nosotros; aunque es pequeño de cuerpo "trepa" las cuestas como si fuera un cabritillo.

Pasamos por la quebrada a la que llaman Pata de Gallina porque — según nos explica el guardabosque- una calle de esas que cruzan por la quebrada va para San Francisco Menéndez; la otra sube hacia Tacuba y la tercera que corre hacia abajo, va para Cara Sucia. Total, las tres calles juntas parece que forman la figura de una pata de gallina.

Por este camino y subiendo esta cuesta me ocurrio a mí una pasada (continuó don Vidal). Yo estaba como de unos 12 años; y todo esto era bosque... de árboles más gruesos que ése (señala un árbol enorme, de unos 40 metros de altura)... a ese árbol le nombran de Mulo.

Venia yo en un viernes santo, después de haber estado fregando con otros cipotes. Era ya como cosa de la una de la tarde... yo iba subiendo esta cuesta ... porque nosotros viviamos en el Plan del Matasano, allárriba. En eso vi un rastro fresquito, como de una persona que iba para'rriba.. pero con los pies para'bajo... en dirección contraria... Como si uno fuera caminando descalzo, pero de espaldas...

El rastro iba fresquito... sobre una gran polvazón.. pero yo no veía a nadie. Pues al llegar a la vuelsa ésa que se ve allárriba... cuando yo voltié a ver... me voltió a ver un hombrecito así... chiquito, a lo más de un metro de altura... gordito y con un sombrerito. Al verme, ya busco la manera de meterse en la montaña. El me voltib a ver asi para'bajo y se metió aquí para'dentro... en esta vuelta. Cuando yo llegué y me acerqué $a$ ver... nada_

Yo le conté después a un señor que se llamaba Teodoro Gómez: Fíjese, $O . .$. que el viernes vi a un cipotío... con los pies al revés. Yo no lo vi bien, sino de lejos. El me voltió a ver, pero después se apuró... no dejo que yo lo viera, porque se metió en carrera Pero ahi estaba la huella... donde se había metido'. '-iAh!, me dijo el señor-, si ese era el Cipitio. Ya te salio a vos también. A mi me ha salido dos veces... iy de día!'

Mientras seguimos cuesta arriba, Ursula recoge un "gallito" que se ha caído de un árbol. Don Vidal le explica que esa planta pertenece al género de las bromelias. Luego, el guardabosque me explica a mi sobre los distintos tipos de Onzas (una clase de felinos) que hay en El Imposible: la Onza Tejón es la más grande... es amarillo, cabezón, porque la cabeza es grandota y redonda. Está también la Onza que llaman Zapatona porque es de patas cortas y gruesas. Es un poco más pequeña que la anterior; $y$ —según el decir del guardabosque - pardiza, casi negra. Y está esa otra que es aplomadita... pareja porque es altita de patas, pero pequeña... Tiene la misma cara de gato que las anteriores. 
'- ¿Y hay Ocelote?' pregunto yo. '-Si, hay... El Ocelote es un tigrillo de los grandes. Porque tigrillo hay de dos ciases: está el tigrillo pequeño, y el tigrillo grande... que le llaman Ocelote.

Ursula comenta —entre cansada y emocionada-: '- ¡Es increíble estar en El Imposible... ipero es posible!, haciéndole de filósofa. En un recodo del camino, un olor penetrante, como de menta, inund6 todo el ambiente. El mismo olor "a montaña" que yo siempre he sentido en las cumbres de Jayaque... cuando he caminado por ahl a eso de las 4 o 5 de la tarde. Ahora tenía que averiguar de una vez por todas qué es lo que produce ese olor tan delicioso. Don Vidal me explica:

El olor se siente por este monte... unos le nombran Zacate de Tunco y otros Zacate de Manteca. Sirve para alimentar a las bestias. Al tentarlo se siente un asunto como si es aceite... aceitoso.

Deshago entre mis dedos un poco de ese zacale y el olorcito se hace aún más intenso. Ahí, ante mis ojos tengo la fuente evocadora de tantos de mis ensueños y viajes por montañas ignotas... Y yo que nunca me habra puesto a pensar en lo obvio: que aquel olor debŕa provenir de algún lado, de alguna planta... quizás porque lo sentía tan del aire, tan de todas partes de la montaña... Ahora, lo retengo entre mis manos, como también lo he hecho con alguna mariposa o con alguna luciérnaga, jugando a capturar por unos instantes los sueños de un niño... Parece mentira: todo lo que es capaz de provocarme una planta, a pesar de su nombre pedestre: Zacale de Tunco...

Y llegamos al propio peñón que le llaman El Imposible. Don Vidal nos dice que antes el cerro donde ahora estamos se encontraba unido por sus dos puntas. Por ahí pasaban sólo indígenas. Pero cierto gobierno trajo presos para que pagaran su condena trabajando aquí. Trabajaban amarrados, colgando de una cuerda sobre el barranco.

Conforme ellos iban tirando piedras, esto se iba haciendo más y más hondo. Habia unos presos amarrados de la cintura trabajando con la piocha. De repente cruzaban el lazo con la piocha... y dicen que varios murieron despeñados.

Primero, el puente fue de madera y alambre; después, hicieron un puente de concreto. Don Eusebio Mezquita, el anterior dueño de esta propiedad, fue el primero en meter carro por aquí.

Desde ese lugar increíble - como lo llamó Ursula - se ven varios cerros: el de Mistepe, el Cerro del León (porque habla muchos leones o pumas), el Cerro del Caballo (porque tiene forma de ese animal). También se ve parte de El Imposible 2, o San Benito. Al lado del puente, que ahora es de cemento y rodeado de mucha vegetacion - de modo que no se ve tan espantable el barranco-, hay un rótulo, una especie de lápida incrustada en una peña: 


\section{EN MAYO DE 1968}

\section{ESTE PASO DEJO DE SER}

IMPOSIBLE.

\section{Bañándonos en las cascadas del río San Francisco}

El descenso desde las cumbres hacia la parte baja del parque fue igualmente placentero. Camila y Ursula saltaban, cantaban y haclan chiste cuando alguien se deslizaba en el lodo o entre las piedras resbaladizas del camino. En la casa de uno de los colonos nos ofrecieron cocos y, después de habernos empachado con el agua y la carne de esa fruta, nos despedimos de don Vidal Campos, prometiéndole regresar pronto al parque para seguir platicando con él.

Saltando de piedra en piedra, nos encontrábamos atravesando el río San Francisco, cuando Carlos nos anunció que su paṕ, don Orlando Santos, venia bajando por entre las peñas del río, después de haber completado su ronda de vigilancia diaria.

El programa "Flor y Canto" de YSUCA saluda a don Orlando Santos, jefe de guardabosques del parque El Imposible. Durante la visita anterior que hicimos a este maravilloso lugar, no pudimos grabar todas las explicaciones que don Orlando nos iba dando sobre los animales y plantas que se encuentran en el parque... Pero ahora, procuraremos no perder palabra de cuanto nos-pueda informer don Orlando..

El jefe de guardabosques nos hablo acerca de los problemas con que se encuentran los vigilantes de El Imposible. El parque, propiamente dicho, consta de unas 5.000 hectáreas de extensión; es decir, 7.000 manzanas; unos $50 \mathrm{~km}^{2}$. Aunque toda el área protegida (que comprende varias propiedades de personas particulares) comprende unas 2.000 hectáreas más. Para una extensión tan grande, sólo hay seis vigilantes mal armados. Por eso -insiste don Orlando- durante el verano es especialmente difícil cumplir con la labor de preservación, porque desde Ahuachapán y aun de Sonsonate llegan partidas de cazadores con toda clase de armas y acompañados de peones y perros. Total, que existen todavía señores que ven el país como su propiedad privada - iaunque algunas zonas sean ya propiedad de todos!-, como su coto de caza o de pesca, al que pueden penetrar cuantas veces quieran, para cobrar las piezas que más les gusten. Ante esa prepotencia e inconciencia de los poderosos de este país, ¿qué pueden hacer seis vigilantes mal armados en El Imposible? Sin embargo, don Orlando tiene plena confianza en que con la ayuda de entidades como el Club 20-30 pueda preservarse lo poco que de fauna y flora aún queda en lugares como El Imposible. 
Don Orlando también es un buen relator de historias y de "pasadas"; así que no fue mucho lo que insistimos para que nos contara sobre el Camarón de Oro, otro de los animales misteriosos de El Imposible.

Hace unos 50 años existía en la poza que ahora llaman de El Encanto, un camarón misterioso. Cuando uno llegaba a la orilla de la poza y veía para'dentro, ahi estaba un camarón grande, como de unos 30 centímetros. Era un camarón brilloso, brilloso, y por eso las gentes decían que era de oro.

Antes, los camarones se cazaban con lazada: en la punta de una vara larga se amarraba un bejuquito y se hacía una lazada. Eso era lo que se metía debajo de las piedras para agarrar a los camarones por la cola. Pero al Camarón de Oro nunca lo lograron cazar... ni con lazada.

Las gentes decian que quien lograra cazar al Camarón de Oro iba a tener buena fortuna y que nadie le iba a ganar cuando peliara.. Pero ninguno pudo con el Camarón de Oro. Desde entonces, le quedó el nombre de poza de El Encanto al lugar.

Las cascadas del paso del río San Francisco constituyen otro de los espectáculos fascinantes del parque El Imposible. Situadas a pocos kilómetros de la entrada del parque, las cascadas se forman porque el agua del río corre deslizándose sobre una caprichosa formación rocosa.

Hace miles o millones de años, una correntada de lava se precipitó en lo que ahora es el lecho del río; al cuajarse, tomó la forma de una gigantesca hogaza. Sobre los accidentes de la roca el agua juega a reposar y aparecen pequeñas pozas en las concavidades, o se precipita en cascadas cuando cae desde las partes más altas a las más bajas de la peña.

En estos mementos (grabo yo) estoy intentando meterme, grabadora en mano, debajo de una de estas hermosas caídas de agua... '-Papi (me grita Ursula, poniendo la voz grave, como de locutora); decí: jen estos mementos la Ursula se está metiendo debajo de una enorme cascada...!"

La grabadora empieza a fallarme y yo tengo que salirme rápido del agua para tratar de componerla. Al poco rato, ya estoy platicando de nuevo con las bañislas:

'-Y a Ud., Margarita, ¿qué le ha parecido este paseo?'. '-Ah, fantástico; nunca crei que iba a venir a un lugar como éste' '- ${ }^{Y}$ ya se metió debajo de alguna cascada?'. '-Si, ya me meti y isimasito me ahogo....'.'-iNo quiere meterse otra vez debajo de una cascada, y conmigo?'. '- iHuy, Dios me libre...!'

Don Orlando nos lleva a un lugar de la orilla del río donde se encuentra un pezote muerto. El animalito murió la noche anterior y don Orlando nos explica 
que la muerte pudo deberse a alguna enfermedad común y corriente, como las que afectan a los humanos; no necesariamente se trata de una epidemia o de rabia.

Nosotros hemos encontrado restos de pezotes que se los ha comido el puma; pero este animalito murio por algún virus... $Y$ es macho, porque le di vuelta y pude darme cuenta...

El pezote es un animal parecido al micoleón, pero con la carita alargada y el hociquito puntiagudo. Pertenece a la familia de los prociónidos. Es, en realidad, el coatí, y es pariente de los mapaches, cercolatos (¿micoleones?) y de los osos panda. En Guatemala, al pezote le llaman pizote; tuve la oportunidad de ver algunos de ellos durante la visita que hiciéramos al zoológico de Petensito, en el lago Petén Itzá. Los pizotes que yo vi en Guatemala eran de color canela y andaban sueltos por el parque, como si fueran perritos domésticos.

El pezote que ahora estábamos viendo tirado en el suelo, boca abajo y devorado par las hormigas, era de color gris óscuro, desde la cola (larga y esponjosa, aunque no tanto como la de un zorro), hasta la cabeza y el hocico. La naturaleza cumplía con su rito, sabio y sagrado: todo lo que muere debe volver a la tierra para convertirse en nutriente y asi permitir que otros seres -animales o plantas- puedan seguir viviendo. Esa es la dura, aunque sabia ley de la montaña ésta de El Imposible.

Hace unos meses (nos platicó don Orlando) andábamos con unos compañeros en la ronda de vigilancia. En eso, en dirección a la Montaña del Ojushtal oímos que ladraba un perro. Nos acercamos al lugar donde se escuchaban los latidos; ya no vimos al perro, pero si las huellas donde habia estado rascando el animal. Era una cueva como de cusuco. Metimos un palo en la cueva y salió un animalito chiquito... se veía que era la cría. Al rato salió el grande... la madre. Nosotros no estábamos seguros qué era, porque se parecía a una ardilla, pero con la cola anillada como de mapache. '-iY qué será?', nos decíamos nosotros.

En eso, como si hubiera adivinado que le estábamos preguntando qué era, el animal empezó a gritar: '-iMuиu... yo! '-iMuu... yo!'. '-iAh, entonces, es un muyo....!', dijimos nosotros. El mismo nos dijo cómo se llamaba..

La cosa era que nosotros sabíamos que los muyos hacian sus nidos arriba, en los palos... pero no sabíamos que tambien Los hicieran en el suelo. como los cusucos... Así que, ya comprobado de qué se trataba, dejamos al muyo con su cría y nosotros nos fuimos a seguir vigilando.

Resulta, pues, que el muyo dice su nombre cuando grita. Me imagino que ha de ser el mismo muyuxe del que nos hablo don Vidal Campos... Lo que pasa es 


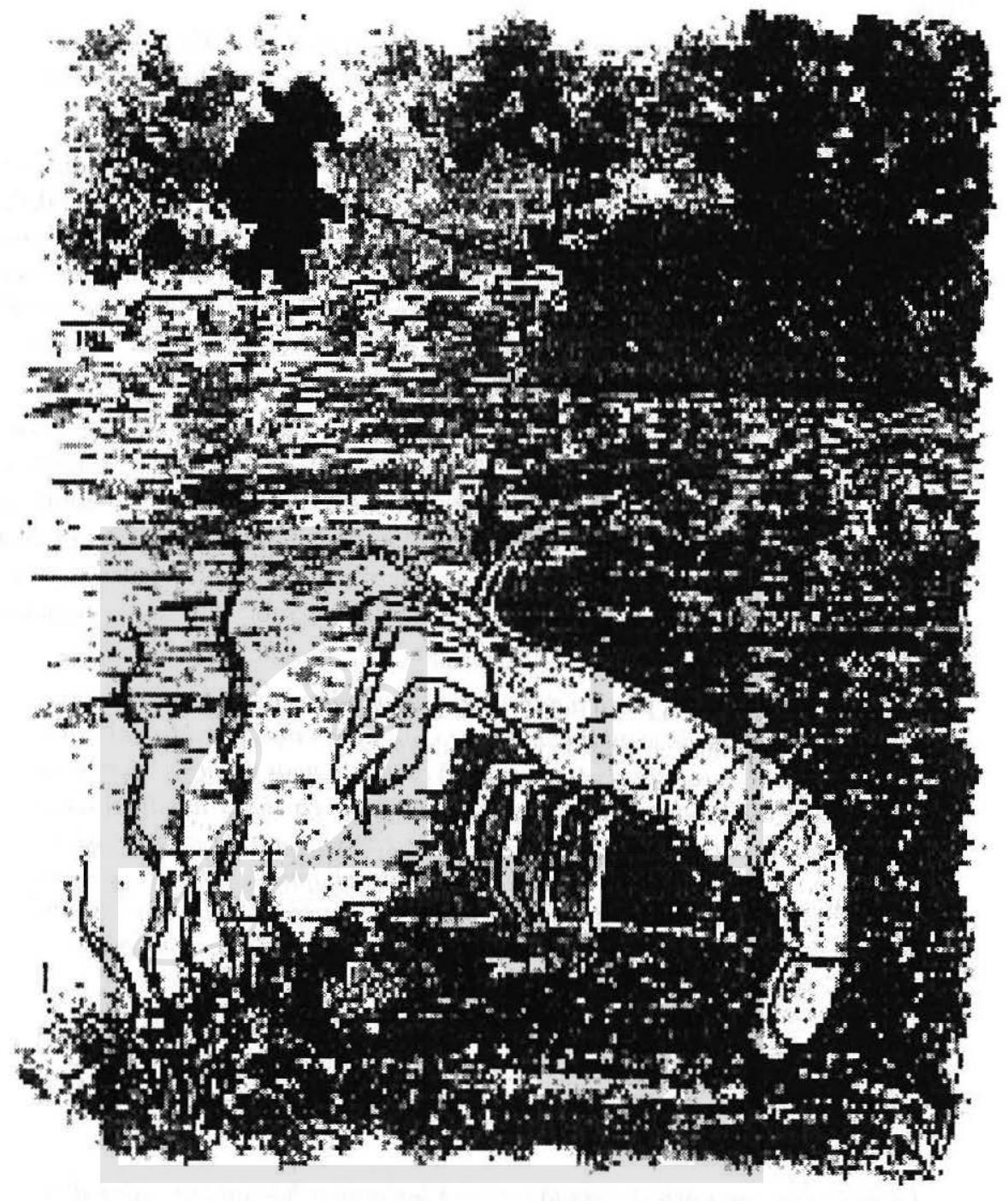

El Camarón de Oro nunca lo pudieron agarrar 
que algunos le oyen el nombre de una manera, y otros, se lo oyen de otra.

Un farallón que se yergue ante nosotros llama mi atención y le pregunto a don Orlando por sus caracteristicas.

A este peñón que tenemos enfrente (responde don Orlando) le llaman el Cerro Tégal... Ahi hay cuestiones arqueologicas... un pedrero bien diferente; por eso tiene ese nombre antiguo. Las piedras están allá'rriba en el mero cerro, donde hay un medio plancito... Aquí vino un norteamericano y dijo que eran cosas antiguas.

La próxima vez que ustedes vengan los voy a llevar alló para que vean esas como lajas de un metro de largo y de un metro de ancho.

Ana María interviene recordando que Carlos, el hijo de don Orlando, le hizo ver unas piedras rollizas, puestas en el camino, que están como enterradas... Son de un color claro amarillento - recalcó Ana María.

Si, en esa parte donde pasaron ustedes hay esa clase de piedras y han de haber sido de algún monumento...

\section{Despedida y cierre del programa Flor y Canto}

Después de bañamos en las cataratas del río San Francisco, nos dirigimos al vehículo dispuestos a emprender el regreso a San Salvador. Pasarfamos dejando a don Orlando y a Carlos en su casa; por eso, yo aprovocharla los últimos momentos para seguir sacándole información a ese amable amigo guardabosque.

En la parte de Loma de Paja se ve bastante venado... Es un jaral... un monte bajo; porque hace unos diez años que no se trabaja. Antes eran potreros pero ahora ya se arborizó: la vegetación estó como de unos diez metros de altura y abajo es jaralillo... Ahi se mantienen los venados; ahí paren las hembras en el mes de mayo...

Un señor tenía un su cultivo de frijol, como de dos tareas... y ni una mata le dejaron: todo el frijol se lo comieron los venados... Siempre que venian mis hijos de la escuela veían ahi a los venados... Es una zona bastante protegida porque los cazadores tienen que pasar por unas veredas que nosotros controlamos más.

Cuando don Orlando nos relata ese episodio de los venados que se comieron las dos tareas de frijol, yo me recuerdo del episodio del Popol Vuh_en que se nos narra algo parecido: los gemelos Hunahpú e Ixbalanqué cultivaban durante el día una milpa y un frijolar; pero durante la noche, los venados y los conejos se comían la cosecha de los dos frustrados gemelos. Tuvieron que poner pajaros que les sirvieran de vigías y así pudieron castigar a los culpables de la destrucción de los cultivos. Eso es lo que le faltó al señor aquél del frijolar: poner como 
vigías a pájaros misteriosos del bosque, o a animales con "virtud".

Vamos saliendo del bosque El Imposible; son las 6 de la tarde, pero parece que son las 7 o las 8 de la noche... tan espesa es la vegetación en esta parte que es llamada la Montaña del Ojushtal..

Don Orlando nos explica que el nombre Montaña del Ojushtal se le ha dado a esta zona porque la mayor parte de los árboles gruesos está constituida por árboles de ojushte.

Hay ojushte de verano y ojushte de invierno. El árbol es grande, como el Arbol de Pan... pero el fruto viene siendo como del tamaño de un jocote de invierno... que es un fruto pequeño. Hay de dos colores: uno rojo y otro amarillo...

Los que se refugiaron en estas montañas en 1932 usaban de las dos clases de ojushte: de invierno y de verano... Recogian canastadas porque esta temporada que pas 6 -por ejemplo- habia para recoger hasta quintales... Y en ese tiempo habia más, según cuentan las personas de más edad.

Entonces, ellos recogian hasta un saco... Ya lo ponian a cocer... por libras. Luego después lo molian y de ahi hacian las tortillas... porque era época de carestía: no había maíz; por eso ocupaban ellos el ojushte... como algo alimenticio.

Interrumpo a don Orlando y traigo a cuento lo que nos decía un guía de Tikal: los mayas habian utilizado un fruto como sustituto del maíz; porque - según el guía- era más rico en proteínas que el mismo maíz. ¿Sería ese fruto el ojushte? Don Orlando cree que se trata del mismo fruto.

Los hechos de 1932 vienen a acaparar de nuevo nuestro interés:

A El Imposible vinieron a ocultarse bastantes gentes que salieron de esos lugares... como de Tacuba. Entonces, en esas cuevas que existen desde hace mucho tiempo... ahi se refugiaron. Esta, por ejemplo, la Cueva de Cal... una cueva grande donde pueden caber unas mil personas... Ahi la gente llevaba maíz, frijol; y ya cuando se escaseaba, salían a conseguir en las montañas el ojushte. '-Sería el equivalente a un tatú de los que hasia hace poco estuvo haciendo la guerrilla... meto yo mi cuchara). "Asi, más o menos'.

Está la otra cueva... la del Altillo; es una cueva que tiene más vista que la Cueva de Cal, aunque es más pequeña. Hay que subir por una roca.. y ya estando alla'rriba hay una parte bien bonita.. y aht hasta se puede dormir uno. Tiene una capa de tierra con arena como de un metro de profundidad... y al ponerse uno a excavar encuentra huesos de seres 
humanos que hace a saber cuántos años que murieron.. Era quizás como un cementerio antiguo. Hay unos huesitos hasta de colores... seguin el tiempo que tienen de antiguos... hasta de color como rojizo.

Esa Cueva del Altillo queda como unos 400 metros después de la Cueva de Cal. Para llegar... se pasa el río de Mistepe y luego se sube una pendiente. Hay una roca... y ahi se llega a la Cueva del Altillo.

Si algún día van ahí.. van a ver un Arbol de Queso... que le llamamos nosotros... o Tambor. Las gentes hicieron ahí como modo de escalera para subirse por una peña. Y ahora el árbol ya creció... se le cayó una parte del cojollo... y ha quedado como forma de escalera Sólo se ven las caladuras que le hicieron con corvo las gentes para subirse a la peha.. Le llaman Arbol de Queso porque la gente aqui lo utiliza para envolver queso: la hoja es bien ancha. El fruto que echa es del tamaño de una naranja... y se lo come el micoleon.

El micoleón es parecido al pezote; sólo que es más grande... la cabecita es redonda La cola se parece a la cola de mico... y el pelo es zaradito. como de león. - ¿Por eso le llaman micoleón, verdad don Orlando (meto yo de nuevo mi cuchara): porque es mitad mico y mitad león?'

En un lugar cerca de donde acabamos de pasar hay dos ceibas que están un poco pequeñas... En ese lugar, cuando todo esto era del señor Eusebio Mezquita, aproximadamente hace unos 40 años... la gente que pasaba de noche, casi toda la gente que pasaba ya de noche, como era más funesto entonces, dicen que salían un montón de animales... patos, chompipes, perros, gatos... La gente decía que era la Legión del Diablo... Salían a asustar a la gente; y ya no pasaban... mejor se regresaban, pero ya no continuaban el camino; porque si no... derechito iban a tener algún problema; por ejemplo, que les quisieran pegar sus golpes por allá o cualquier cosa así...

Ahora esos animales ya no salen; pero hace como un año... a un colono y a su hijo les salió un caballo. Venía el hijo y venía el papá. Ellos tenian un sembrado por ahi; entonces, dicen que vieron el caballo en la calle. '-iMirá -dicen que le dijo-; ese caballo nos va a comer la milpa'. '- iAh, no creo; pero bien.. lo vamos a arriar'. Entonces vinieron ellos y dijeron a arriar el caballo... y la sorpresa grande que tuvieron ellos fue que el caballo en vez de agarrar para'bajo, para donde ellos lo arriaban, se les tiró encima.. Entonces se apartaron y agarró para el lado de la milpa. Ellos le salieron adelante para arriarlo... para que no se metiera a la milpa. Y el caballo dijo de vuelta; se cruzó la calle y en un izas! -que uno dice-el animal se fue yendo para el lado del río... Bien herrado se oía que iba el caballo... Era un caballo prieto... 
Entonces dijeron ellos a buscar huellas, y no hallaron huellas de caballo...

Se cree que existen esas cuestiones de sustos por ahi... en las ceibitas... abajo de la ceibona grande. La próxima vez vamos a ir a ese lado...

Llegamos al portón de entrada de El Imposible y, como ahí está la casa de don Orlando, nos despedimos de él y de Carlos. Enseguida, cada uno de nosotros fue grabando sus palabras de despedida para los oyentes del programa Flor y Canto. Ana Maria fue la primera:

Hemos terminado nuestro paseo por el mundo mágico del bosque El Imposible... Y todos los encantos relatados por sus protagonistas, don Vidal y don Orlando, fueron trasladados a ustedes en la voz viva... gracias al equipo expedicionario de Flor y Canto...

Luego le tocó el turno a Camilita, a Ursula y a Margarita:

'Y ahora Camilita va a decir unas palabras de despedida..' (imposté yo la voz). '-Mi mami está sentada..'. '- $Y$ Y viste al animalito muerto?' '-Sí.. estaba ahí... tirado'. '-La Ursula también va a decir unas palabras de despedida... : '-Bueno, para mi realmente ha sido un viaje fantástico... Yo, primero, no quería venir; pero yo sabia que si no venía, mi papá me iba a decir: ¿Fijate de lo que te perdiste; porque siempre los viajes de Flor y Canto son asi!'. '-Y Margarita... ¿qué nos va a decir?' (acerqué la grabadora a la aludida). '-Bueno, que me gustó todo, porque yo nunca habia venido aquí.. Me gusto bastante el río en que nos fuimos a bañar... estaba bien heladita el agua... Me encantó'.

El vehículo saltaba como si fuera yegua desenfrenada, porque la carretera desde San Francisco Menéndez a Carasucia, sobre todo, está llena de baches y mal cuidada. Ya llegando a Sonsonate empieza a mejorar. Sin embargo, nosotros segufamos afanados grabando nuestras impresiones para el programa de radio. Un momento de la grabación quedó especialmente gracioso - aunque doloroso para quien lo sufrió-. Mientras don Orlando nos contaba sobre el caballo diabólico que se les apareció al colono y a su hijo, Ana María pegó con la cabeza en el techo del vehículo... La grabadora captó fielmente primero el ipum! y luego el jay! que le dieron más verismo al cuento del caballo relinchón.

'-La reflexión final (dije yo) la dejamos para Oscar Edgardo Melhado...' (Oscar, aunque manejando, empezó a grabar): '-Para despedimos de El Imposible no tenemos palabras... Lo que hemos visto, el relato, la descripción... tienen la fuerza suficiente para hacemos imaginar la realidad ésa tan rica.. Mis palabras, entonces, salen sobrando... Por eso, solo podría añadir unas breves reflexiones: primero, la fuerza que uno siente al estar en contacto con la naturaleza; al estar en un mundo mági- 
co, en un bosque encantado... como es el bosque de El Imposible. Y esto, de alguna manera, hace que uno mantenga la esperanza en el país... porque el hecho de que existan estos parajes mágicos implica que tal vez en el fondo de los salvadoreños hay poesía... El venir a estos lugares, ciertamente, le refresca a uno el espíritu y la mente.

Segundo: así como el bosque El Imposible... hay otros lugares aqui en nuestro país. Se está hablando de unas ciento dieciocho áreas protegidas que se pueden manejar como parques nacionales... Es decir, como estos parajes de El Imposible, hay muchos... Y esto me recuerda algo que decia García Márquez: las cosas tienen su espíritu propio, y lo que hace falta es despertarles ese espíritu... Nosotros, adentrándonos a El Imposible, hemos sentido despertarse nuestro espíritu... y nosotros también hemos desperiado un poco el espíritu de El Imposible... Pero asi hay otros sitios que necesitan ser despertados en el espiritu.

$Y$ lo tercero: la armonía con la naturaleza, con los animales; en el entendimiento con la vegetación. El estar en lugares como El Imposible le da pauta a uno para pensar que la poesía no es sólo literatura, sino que la poesía es vegetación; y dependiendo de cómo nosotros nos integremos y armonicemos con nuestro media ambiente, y dependiendo del espiritu y de la actitud de nosotros ante la naturaleza, así son las compensaciones que le da la naturaleza a uno. De alguna manera, el hecho de que nosotros apreciemos eso, es lo que nos ha dada la pauta para observar ese bosque con un lente más artistico, con un lente más espiritual. $Y$ con estas palabras, Flor y Canto se despide de su fantéstica expedición al bosque El Imposible...

Así terminó nuestro paseo, aquel $1^{\circ}$ de noviembre de 1992. El Imposible nos había fascinado, y no fue "posible" romper aquella fascinación - como la de la masacuata de fray Francisco Ximénez-, a pesar de que medió el agua entre nosotros y la montaña "constrictor" (o apretadora). Porque cuando ya fbamos llegando al puente famoso que le da el nombre al lugar, ofmos un ruido como de correntada de río. "- ¿Y qué río es ese que estamos escuchando tan alto en la montaña?', le pregunté yo a don Vidal Santos. '-Si ése no es ró... isi es Elver...!' me contestó riéndose Oscar. Efectivamente, al poco rato nos estaba cayendo el aguacero. Menos mal que fue pasada de nubes, y enseguida pudimos contemplar el espectáculo grandioso de los cerros dialogando con las nubes.

Nos devoro El Imposible; ya somos parte de su esplritu, del "juelgo" de sus montañas y bosques. Y el agua, en ello (como la de las cascadas o de la lluvia), sólo sirvió para acrecentar y sellar nuestra pertenencia a ese bosque encantado. Ya somos posesos, jugados por ese bosque, como quien cae presa también de la Utopía. Porque Imposible y Utopía vienen siendo la misma cosa, aquí en El Salvador. 
Pensar, por ejemplo, que los salvadoreños habrán un día de respetar su suelo patrio, que decidirán reforestarlo y vivir en armonfa con animales y plantas, es un sueño imposible. Por eso, en el parque El Imposible está ençarnado un sueño que quizás nunca va a ser realizable: que todo el país vuelva a ser como él, como El Imposible; que ese pedazo de armonía con la naturaleza llegue a hacerse extensivo a todo El Salvador, es algo que estŕ totalmente fuera de nuestro alcance, a pesar de lo que sugieren las optimistas palabras finales de Oscar.

Ya no es posible revertir procesos de destrucción y de desortización. Dicen algunos entendidos que para evitar ese daño irremediable que se avecina para El Salvador, habría que reforestar $8.000 \mathrm{~km}^{2}$ : jmás de la tercera parte del país! Con tanta población que tenemos y con tan poca conciencia ecológica que nos caracteriza, ese proyecto es prácticamente inviable, irrealizable, jimposible!

Por eso El Imposible es un tesoro; un lugar donde quedan en suspenso las dimensiones normales del tiempo y del espacio. Porque ese parque es uno de los últimos rincones donde aún es posible la Utopla. Y a ese dato nos aferramos - parafraseando a Oscar- los que todavía tenemos esperanzas en un nuevo El Salvador.

Por eso nos fascinó y nos seguirá fascinando El Imposible. Por eso se mete dentro de nosotros como un sortilegio, como una posesion bendita de la que ya nunca quisieramos liberarnos, jaunque amanecen tomentas y aguaceros!

Cuscatlán, 14 de diciembre de 1992 